\title{
Late-Life Depression, Cognitive Impairment, and Relationship with Alzheimer's Disease
}

\author{
Sandra Invernizzi Isabelle Simoes Loureiro Kendra G. Kandana Arachchige \\ Laurent Lefebvre \\ Department of Cognitive Psychology and Neuropsychology, University of Mons, Mons, Belgium
}

\section{Keywords \\ Depression · Elderly · Cognition · Dementia · Comorbidity}

\begin{abstract}
This narrative review aimed to explore the existing knowledge in order to examine the multiple forms of late-life depression (LLD) within a non-neurodegenerative or a neurodegenerative context, in particular Alzheimer's disease (AD). This review will first provide information about different pathogenic hypotheses proposed to describe LLD when it is not linked to a neurodegenerative context. Within the presentation of these syndromes, the literature reports thymic and cognitive specific features and highlights a common preponderance of cognitive impairment, and particularly executive. This review will also report data from research works that have addressed the role of depressive symptoms (DSs) in incidence of $A D$ and mild cognitive impairment $(\mathrm{MCl})$ conversion to $A D$. These findings support the claim that the relationship between DS (or LLD) and the cognitive decline encountered in AD can be of 2 types: (1) risk factor or (2) prodrome. They also support the hypothesis that the effect of DS on the incidence of AD can be identified between specific characteristics of these symptoms such as a very first apparition late in life, an increasing severity of DS, and a poor
\end{abstract}

response to medical treatment. Finally, longitudinal and cross-sectional research will be presented, aiming to identify the predictive value of DS (or LLD) on AD incidence and/or conversion of $\mathrm{MCl}$ (and specifically amnestic $\mathrm{MCl}$ ). This final section shows that specific features of LLD, such as being of early- or late-onset, can be considered as indices of AD incidence.

(c) 2021 S. Karger AG, Basel

\section{Introduction}

The prevalence of depression increases from 5 to 10 $20 \%$ when it occurs in the ageing population (from 60 to 65 years old) [1]. In addition, elderly individuals are more vulnerable to the damaging effects of depression $[2,3]$, threatening their vital diagnosis due to the rapid deterioration of their general health, the substantial recurrence rate [4], and the number of successful suicides [5]. The recurrence rate can be reduced by making a diagnosis from the first episode, less severe than the subsequent ones [6], and by adequately managing it [7]. The diagnosis model based on younger adults' criteria has now been demonstrated to be inappropriate in the ageing context $[8,9]$. Moreover, several hypotheses of late-life depres- 
sion (LLD) vary in their pathogenic origin and their clinical (thymic and cognitive) profile. In addition, their frequent comorbidity with dementia [10] and in particular with early stage of Alzheimer's disease (AD) [11] increases the complexity of the diagnosis. It is therefore critical to distinguish between a LLD including cognitive disorders and early $\mathrm{AD}$ accompanied by thymic symptoms. In LLD, the treatment of thymic symptoms is associated either with an improvement (in 42 [12] to $45 \%$ [13] of cases) of the cognitive deficit or with a persistence of the cognitive deficit without an increment [14]. In AD, thymic symptoms are expected to disappear on their own with the progression of the disease [11], while the cognitive symptoms will irreversibly increase [15]. Given the similarity of the thymic symptomatology, the cognitive criteria inherent to each situation represent a key issue in geriatric neuropsychology research.

\section{Definition of LLD}

Amongst the important varieties of LLD situations (i.e., bipolar, hypochondriac, hostile, conative, anxious, or melancholic) [16], this article focuses on unipolar depression whose cognitive expression may lead to diagnostic ambiguity with AD. Because the Diagnostic and Statistical Manual of Mental Disorders (DSM 5) [17] does not provide a specific diagnosis for LLD (after 60 years of age), the criteria for major depressive episodes (MDEs) (code 296) or recurrent depressive disorders (code 300.4) are used. The diagnosis of MDE requires at least 5 depressive symptoms (DS) amongst depressed mood, anhedonia, weight changes (excessive gain or loss), sleep disturbances (hypo- or hypersomnia), psychomotor rhythm disorders (restlessness or slowing down), feelings of tiredness, negative feelings about the self (guilt and worthlessness), concentration disturbances, or recurrent morbid thoughts (thoughts of doom or death) [17]. These depressive features are also encountered in the geriatric context but the symptomatologic profiles will be influenced by age, making the outlined diagnostic model unsuitable in many cases after 60 years of age [16]. A depletion syndrome was proposed in the 1980s, characterized by symptoms of hopelessness, loss of appetite, loss of interest, and thoughts of death. Later, Yesavage [8] suggested that the specificities of MDE diagnosis in the elderly would not be characterized by specific symptoms but rather by their aetiology, intensity, and the way they affect daily life activities. The diagnostic approach for the elderly therefore relies on a cautious use of the DS termi- nology for age-related physical and psychologic characteristics that are not necessarily indicative of a depressive state. Indeed, when encountered in elderly, the symptomatic features of depression among younger adults (such as decreased appetite and energy, altered sleep patterns, a loss of interest in activities, somatic complaints, or psychomotor slowing) may be due to ageing and not symptomatic of any disease. But, in contrast, these traits cannot be excluded from the diagnostic picture of depression in the elderly, as not all situations of ageing are necessarily associated with all of these traits. To address this difficulty, some authors suggest the use of the DSM 5 diagnostic criteria, even for the elderly, not by measuring the number of symptoms but by assessing the intensity of their expression. Nevertheless, symptoms like anhedonia, lack of energy, feelings of guilt, and suicidal thoughts [14, 18-20] are still reported to be prevalent in LLD, whereas feelings of sadness/dysphoria are not [9]. Cognitive impairment may also be characteristic of LLD, along with a state of anxiety, especially in the morning (which is predictive of a poorer response to pharmacologic treatment) [9]. For all these reasons, several diagnostic scales used for MDE are not adapted to the geriatric context. The Beck Depression Inventory (BDI II) [21] does not distinguish anxiety from depression and gives an overriding importance to somatic complaints (easily confused with the effects of ageing). The Centre for Epidemiologic StudiesDepression (CES-D) [22] contains several items (i.e., value given to life, hopes for the future, or suicidal intentions) that lead to interpretation issues [9]. Furthermore, these scales do not include measures of cognitive concerns or cognitive impairment. In contrast, the Geriatric Depression Scale (GDS) has been created for the gerontological context and includes fewer somatic items, evokes cognitive concerns, and is based on a dichotomized response mode. This questionnaire is also centred on the feelings of the last few weeks [23], allowing measurement of recent changes on comparison to prior behaviour and avoiding the confusion with a general perception of the ageing process.

\section{DSs in Late-Life without Dementia}

Geriatric dysexecutive depression syndrome (GDDS), vascular depressive syndrome (VDS), and depressive with reversible dementia syndrome (DrdS) are different situations of LLD, each resulting from pathogenic hypotheses unrelated to dementia. These syndromes are distinct in their thymic and neurocognitive features [19]. 
This GDDS $[9,14,18-20,24]$ is reported to present significant cognitive impairment, limited neurovegetative complaints, dominance of traits of anhedonia, agitation and guilt, together with traits of psychotic disorders (lack of insight and suspiciousness). This pathology is further complicated by a poor response to antidepressants, little remission [13, 25-27], and a high relapse rate [18]. In GDDS, the cognitive disorder seems to persist even after thymic remission, presumably related to the dysexecutive disorder [24-26]. Indeed, a negative correlation between dysexecutive symptoms and remission rates has been demonstrated [25-28]. This non-remission situation differentiates GDDS from depression encountered in adults under 60 years of age. In the latter, when cognitive dysfunctions persist after therapy, they involve impairments in verbal learning and memory [29] that are better explained by the expression of premorbid vulnerabilities than as a consequence of depression [29]. However, it must be noted that the executive deficit can also coexist with depression before the age of 60 [29]. But, in the case of later life, the impairment is amplified and will mainly affect inhibition [24] and cognitive flexibility [24, 26]. The VDS is an alternative pathogenesis that occurs when a link can be found between MDE and a vascular injury or a stroke [18]. The VDS is reportedly associated with a late-onset LLD (i.e., when the very first MDE only occurs after the age of 60) rather than with an early-onset LLD (i.e., when the LLD is preceded by recurrent MDE before the age of 60), although this association is not an exclusive condition [18]. The VDS does not differ much from the other LLDs in terms of thymic and cognitive profiles [18], besides complaints about the ability to concentrate [30] and the absence of guilt [9]. Some authors have suggested a common vascular cause for LLD and cognitive decline in ageing. According to this hypothesis, a dysfunction of the immune system resulting from ageing would lead to a chain of biochemical events resulting in a chronic pro-inflammatory state which would then become the common risk factor [18, 31]. However, this assumption has to be considered in light of data which do not support it, particularly in the important retrospective Whitehall II study that highlighted an absence of effect of a vascular syndrome on the correlation between DS and cognitive decline [31]. In their results, regardless of whether the vascular data were included or not, the correlation remained similar. Finally, the third syndrome mentioned, DrdS [32], replaces the notions of "depressive pseudo-dementia," and "pseudodemential depression" that existed in clinic in the 1980s but were largely discarded for being too inaccurate in terms of di- agnosis. The DrdS is a pathologic condition characterized by a confirmed diagnosis of MDE and a cognitive decline that differs from dementia only by its reversibility, with scores on mini-mental state evaluation [33] increasing over 21/30 after remission of the depressive state [34]. Also characterized by predominant traits such as morning awakening, loss of sexual desire, and psychic and somatic anxiety [32], this notion of DrdS has little support in the literature.

\section{Cognitive Specific Impairment in LLD with Non- Demential Pathogenesis}

Cognitive impairment is a central feature of LLD, with disorders that are more severe than in case of depression before the age of 60 . Indeed, as cognitive impairment before the age of 60 is dominated by the dysexecutive syndrome and often accompanied by impairments of attentional, psychomotor, or short-term memory functions [29], Thomas et al. [35] showed that $\operatorname{LLD}(\geq 60)$ is associated with more severe impairment in verbal learning, memory and motor speed than depression in earlier adult life. Depression is added as a vulnerability factor to the alterations in cognitive abilities already encountered in healthy ageing and this combination leads to a more significant and extensive cognitive impairment $[9,14,18$, $24,32,36,37]$. This impairment will primarily express itself in declarative memory $[25,26]$, mainly episodic [25], but it is proposed to rely on a form of executive semantics [25]. Indeed, during recognition of learnt words tasks, low scores will be associated with an absence of semantic organization strategies during the encoding phase, relying on executive semantics (i.e., selection and inhibition of the concepts) more than on a true impairment of the memory $[20,25]$. Also impacted by LLD are general executive functioning $[14,19,20,24,38,39]$, attention $[24,26]$, information processing $[25,26]$, visuospatial [25] and language [24] skills, learning [26], and the ability to perform verbal fluency $[9,26,38]$. The situation of fluency tasks is particular because fluency performance may be based on executive functions, language, or psychomotor slowing (for review [38]). Therefore, in the case of LLD, deficits in sustained attention, concentration, and recall speed are thought to be the main causes implicated $[9,38]$. There are varying reports and interpretations of research regarding the impact of LLD on brain structures and neurocognitive outcomes. Some of them point to a change of grey matter volume in the prefrontal [25, 40-42] (orbitofrontal [25, 40,41] and dorso- 
lateral $[25,40])$, medial-temporal $[25,40,41]$ and subcortical $[25,41]$ structures (hippocampus $[25,41]$, anterior cingulate cortex [25], and striatum [42], and brainstem [42]). These structural impairments could explain the reduced performances on episodic recall tasks. Indeed, the prefrontal structures are involved in encoding [25], while the hippocampus contributes to the consolidation of information $[43,44]$ and error control during response [45], and the anterior cingulate cortex to organizational strategies during learning $[25,46]$. An association has been demonstrated between the vulnerability of prefrontal structures and low performance on word recognition tasks in LLD, suggesting that the memory deficit in this context is related to the subjective organization of information [47] and its executive dimension $[20,25]$. Indeed, prefrontal structures facilitate the use of contextual associations during encoding, which strengthens memory by creating cues for retrieval [48]. Kohler et al. [41] have shown, however, an absence of association between these deficits and a reduction in cortical mass, either for the whole brain, the prefrontal lobe, or the hippocampus. Rather, they associate white matter hyperintensities with memory, dysexecutive, and processing speed impairments in LLD. In a recent systematic review, Kim and Han [49] reported research supporting a model linking white matter hyperintensities with emotion regulation and cognitive regulation processes in LLD. Their report of literature indicates that the intensity of white matter, proposed as a key construct of vascular depression, is strongly associated with cognitive impairment, especially for executive function and processing speed because of the disconnection it caused between several brain networks. At first, this disconnection syndrome hypothesis concerns a Default Mode Network [49] that involves the medial prefrontal and posterior cingulate cortices, the precuneus and medial-temporal lobe and is highly related to regulation of emotion. Secondly, this disconnection syndrome hypothesis touches a Cognitive Control Network [49], that involves dorsolateral prefrontal, dorsolateral anterior cingulate, and posterior parietal cortices, and is strongly associated with cognitive functioning, and thirdly the frontostriatal network [24, $38,42,50,51]$, which dysfunction is common to many psychiatric disorders [38]. The review by Kim and Han [49] therefore supports previous research [50, 51] proposing a pathway linking depression to cognitive impairment by a model that includes the disconnection syndrome hypothesis and the vascular depression hypothesis.

Depression, Cognition, and Alzheimer

\section{LLD and Its Incidence on AD}

The DS are found in the context of various form of dementia. Indeed, they are associated with $20-30 \%$ of AD (before the mild stage [37]), 20-50\% of Parkinson's type dementia [10] and 50\% of vascular dementia [37], frontotemporal dementia [10], and Lewy body dementia [37]. While most of these neurodegenerative disorders have a distinct symptomatology, in early $\mathrm{AD}$, the thymic and cognitive profiles will present numerous similarities with LLD, making them difficult to differentiate [52]. Early $\mathrm{AD}$ is a neurodegenerative disorder for which the diagnosis is established according to the NINCD-ADRDA [15] criteria, associating histopathologic evidence with a deficit that affects at least 2 cognitive domains, including memory, with a significant impact on the patient's daily life. The cognitive impairment primarily involves declarative memory, followed by attention and short-term memory [53]. The DS encountered in the early stage of the disease tend to disappear as the pathology progresses [11]. For the past 2 decades, the early stage of AD has been considered in relation to mild cognitive impairment (MCI), which is often mentioned as a preliminary stage of $\mathrm{AD}$. This MCI [54] may indeed evolve to a neurodegenerative disorder and, in several cases, to AD. Over time, the literature has made a distinction between amnestic MCI (aMCI; either single domain, when only memory is impaired, or multiple domains, when besides the memory deficit, at least another cognitive domain is impaired) and non-amnestic MCI [54, 55]. Typically, the former (aMCI) is suggested as a possible prodrome of $\mathrm{AD}$ [56]. Given this context, it is worthy to question the relationship of LLD with the incidence of $\mathrm{AD}$ and the evolution of aMCI. In reviewing the literature, we shall distinguish (a) research-evoking DSs (in the sense of standardized test results) from research that have used a formal diagnosis of LLD [17], and, in the same order of idea (b) research-evoking cognitive decline from research that has included $\mathrm{AD}$ diagnoses. Regarding the relationship between LLD (or DSs) and AD (or cognitive decline), some models propose that cognitive decline precedes DSs (either as a risk factor $[47,57]$ or trigger [57]) and others propose that DSs precede cognitive decline (either as a vulnerability factor [24, 25], a trigger [57], a risk factor [31, 57-59] for $\mathrm{AD}$, or part of its prodrome [57, 60-62]). The situation in which DSs precede cognitive decline appears to be more supported by the literature. A 12-year longitudinal investigation showed that the presence of DS was predictive of faster memory decline, but not the contrary [57]. The Whitehall II study (2010) examined this

Dement Geriatr Cogn Disord 2021;50:414-424 417 
association over an 18-years follow-up [31]. In this study, frequent DSs were associated with a decline in episodic memory, language, and fluency performance. The authors also showed a difference between the effect of DSs assessed at the beginning (1-9 years) and at the end (1018 years) of follow-up. Assessment showing the presence of DS at early follow-up was only associated with decline in episodic memory and semantic fluency performance, whereas at late follow-up, they were associated with a broad cognitive decline [31]. This difference can be considered in the framework of the early- and late-onset differences between LLDs and supports the hypothesis of a common pathogenic cause between late-onset depression ( $>60$ years) and the broad cognitive decline encountered in neurodegenerative pathologies [57,60-62]. The hypotheses of depression as a risk factor or as part of the prodrome of $\mathrm{AD}$ are not mutually exclusive, although their distinction is important. Indeed, the treatment of $\mathrm{DS}$ caused by AD will not influence the course of the disease. These DS will initially be resistant to treatment $[9$, $18,51]$ but will fade with the progression of the disease while cognitive symptoms will increase because of the neurodegenerative context. Three pathogenic hypotheses appear to link LLD and AD, firstly, the existence of a common deleterious effect of beta-amyloid plaques and neurofibrillary deposits for both conditions [63]. This neurophysiological condition, found in both $\mathrm{AD}$ without DSs and in LLD without AD, do not allow the differentiation of the diagnosis, although the accumulation of beta-amyloid plaques in the hippocampus of $\mathrm{AD}$ is demonstrated to be even more important if they have suffered repeated depressions $[18,63]$. Secondly, a part of the literature supports the idea of a common inflammatory situation, already evoked in the VDS [18]. Finally, a last hypothesis supports that the disturbance in the hypothalamic-pituitary-adrenal axis causes long-term hippocampal atrophy [64]. The mechanism is that overactivated by depression, this axis causes a neuroendocrine response similar to that caused by stress with an impaired balance of glucocorticoid receptors [64].

\section{Are DS Predictive of AD Onset?}

Longitudinal and cross-sectional research has been conducted to identify the predictive value [65-68] of DS (or LLD) on AD incidence and/or conversion of MCI (and specifically aMCI; Table 1). Findings from 2015 show that the risk of $\mathrm{AD}$ incidence is nearly doubled when associated with late-onset LLD (with a very first ep- isode after age 70) and are increased by four-fold when associated with severe LLD [69]. A 2-year research by Mirza et al. [70] compared the effect of several development paths of DS on the incidence of dementia (including $\mathrm{AD})$. The alternative pathways combined mild and severe DS, depending on whether they remained stable, increased, or decreased over time (even decreasing until complete remission). The results of this study show that it is the increase in depressive symptoms over time that is more significantly associated with a risk of developing $\mathrm{AD}$ [70]. Kida et al. [71] support the existence of an association between the risk of conversion of aMCI and the increase of DS over an 8-year period while Defrancesco et al. [72] show that the rate of conversion of aMCI was proportionally increasing with the severity of DS (measured with the GDS 30 [8]), with 42.5 to $54.4 \%$ of conversion for severe ( $>15$ at GDS 30 ), to very severe ( $>20$ at GDS 30 ) DS. Ohanna et al. [73], however, did not show an association between higher severity of the first MDE and the incidence of AD. Instead of that, it did show an impact of the duration of the first MDE on the incidence of a neurodegenerative disorder, including $\mathrm{AD}$ in $76 \%$ of cases. The idea of a stronger association between late-onset LLD and the incidence of $\mathrm{AD}$, which is part of a hypothesis that this late-onset of depression is a prodromal sign of the disease, is supported by several research studies. Indeed, Heser et al. [74] highlighted a significant association between late-onset LLD ( $>75$ years) and the incidence of AD (3-fold risk). Similarly, Dillon et al. [75] showed this association with patients who reported the first MDE after age 65. Tapiainen et al. [76] showed an effect of DS on AD incidence when they were identified during the 5 years prior to the diagnosis of AD but not when they were identified earlier than 5 years prior to this diagnosis. Barnes et al. [77] also demonstrated that, compared to early-onset LLD (age: $53 \pm 4$ ), late-onset LLD (age: $75 \pm 3$ ) doubled the risk of developing $\mathrm{AD}$, while it increased the risk of developing vascular dementia by $50 \%$. Finally, by analysing the composition of depressive symptomatology, Shdo et al. [78] were able to distinguish AD patients from patients with other dementias. High levels of the DS "worry about cognitive functioning" with low levels of the DS "general worry," low "withdrawal" tendency, and low "hopelessness" permitted to identify $76 \%$ of AD patients. Seeking the histopathologic mechanism, Harrington et al. [79] showed a higher presence of beta-amyloid 40 and 42 in individuals with dementia when they had experienced late-onset LLD compared to those whose dementia was associated with early-onset LLD. Another research by Lloyd et al. [80] showed a more significant alteration in 


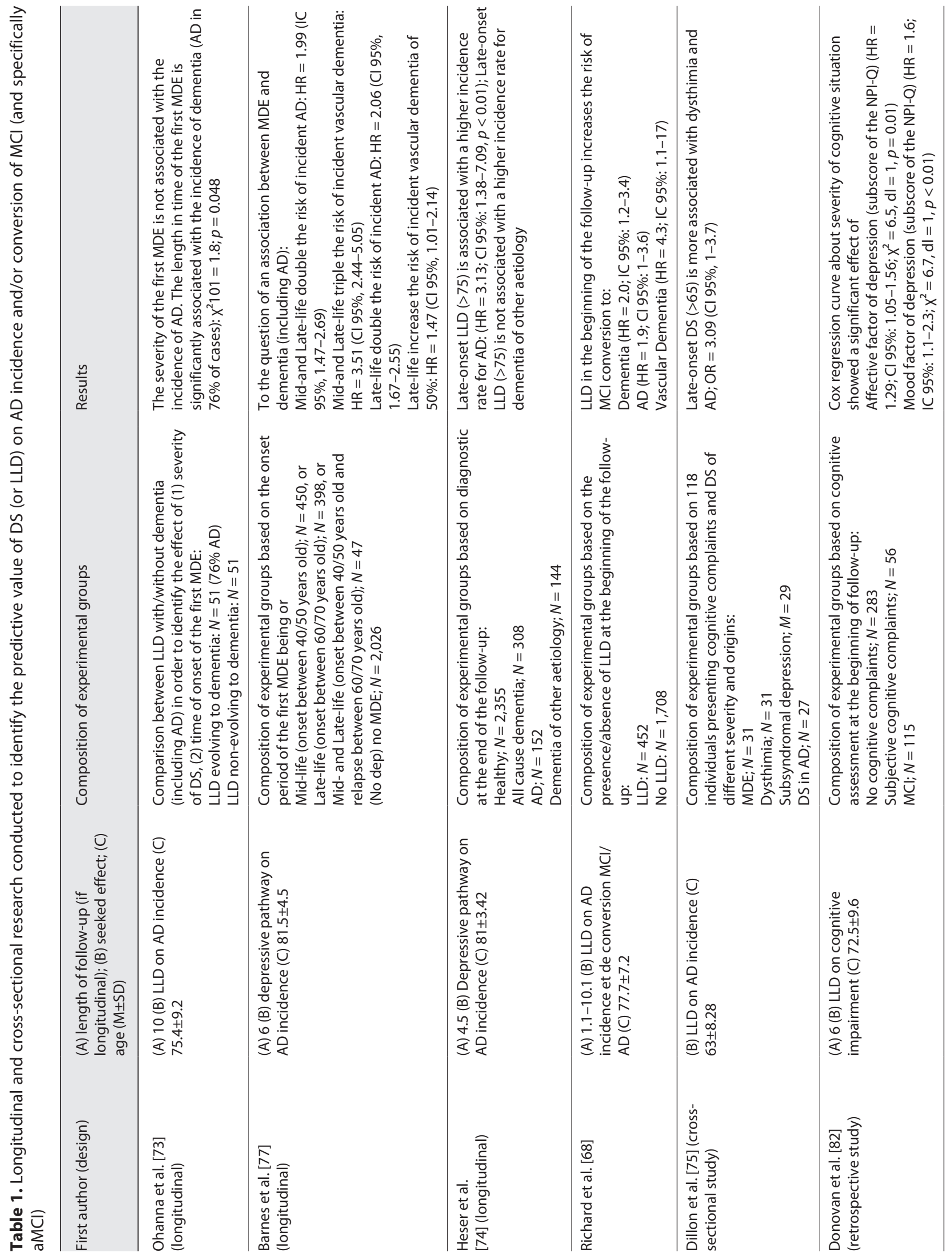




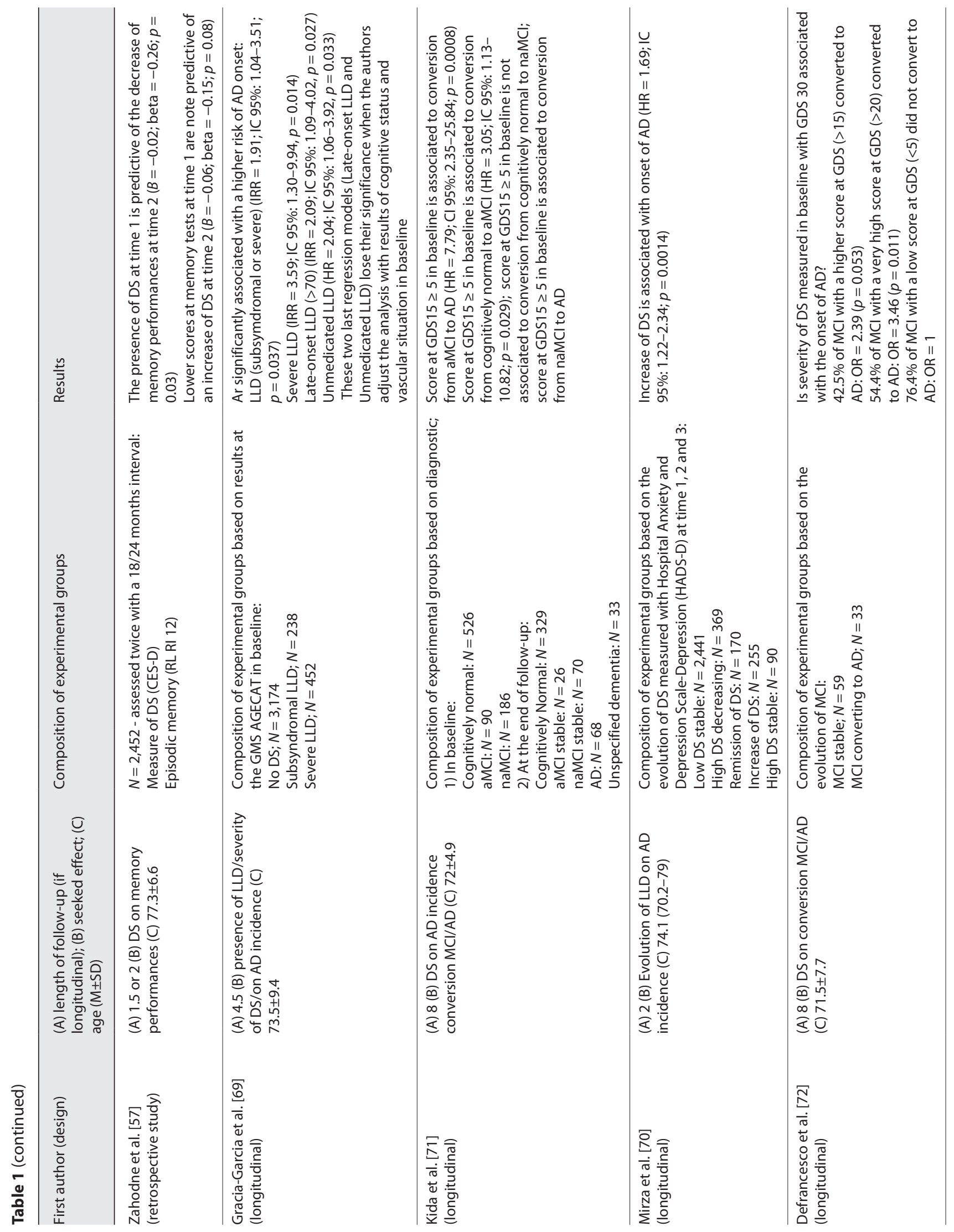




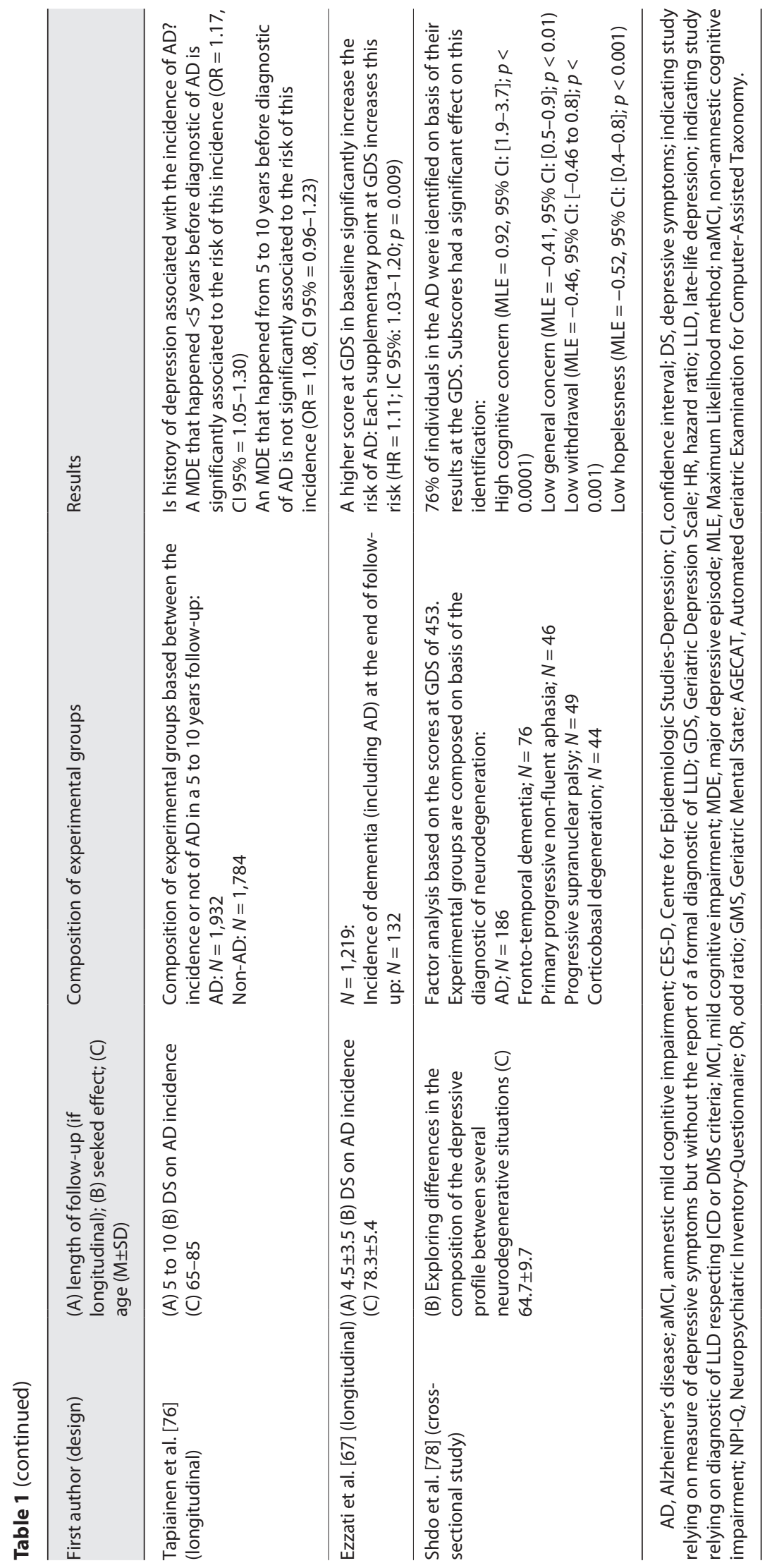


hippocampal volume in late-onset LLD than in early-onset LLD. Their results go against the hypothesis that hippocampal alteration is determined by the repetition of MDE during life (as it is the case in early-onset LLD) and their consequence in terms of overactivation of the hypothalamic-pituitary-adrenal axis [80, 81].

\section{Conclusion}

This review allowed us to point out 3 features of interest in the process of a differential diagnostic approach between LLD and LLD when linked to AD. Firstly, several investigations have led us to consider a difference in cognitive impairment, with a pronounced dysexecutive profile in LLD alone and a broader impairment profile in LLD when encountered in the setting of AD. Secondly, regarding the memory impairment, visible in both conditions, it seems useful to investigate the likelihood of a different functional origin. While impairment of the temporal areas causes the declarative memory deficit in $\mathrm{AD}$, in LLD not related to $A D$, it seems to be more a matter of executive semantics which dysfunction prevents efficient encoding during recall tasks. Thirdly, research seems to support the existence of an association between late-onset LLD and the prodrome of $\mathrm{AD}$, which could sustain the idea of a different pathogenesis for late-onset LLD compared to early-onset LLD. This hypothesis feeds the idea that even if the accumulation of MDE throughout life leads to a biochemical chain of events that render the brain areas primarily affected by $\mathrm{AD}$ (notably the hippocampus) vulnerable, in the case of late-onset LLD, depression would not be a risk factor but rather a consequence of the neurodegenerative process. This difference is essential to consider, both for the management of DS and for cognitive management.

\section{Conflict of Interest Statement}

The authors have no conflicts of interest to declare.

\section{Funding Sources}

First and third authors work under a doctoral grant and benefit of no other funding. Second and last authors work in the framework of their academic nomination and benefit of no other funding.

\section{Author Contributions}

First author reviewed the articles included in this synthesis and proposed the first draft. Second and last author contributed to the critical analysis of the article and to the finalization of its writing. Third author performed proofreading and contributed to the finalization of the manuscript.

\section{References}

1 Kessler RC, Berglund P, Demler O, Jin R, Merikangas KR, Walters EE. Lifetime prevalence and age-of-onset distributions of DSMIV disorders in the National Comorbidity Survey Replication. Arch Gen Psychiatry. 2005;62(6):593-602.

2 Schaakxs R, Comijs HC, Lamers F, Kok RM, Beekman ATF, Penninx BWJH. Associations between age and the course of major depressive disorder: a 2-year longitudinal cohort study. Lancet Psychiatry. 2018;5(7):581-90.

3 Evans J, Charness N, Dijkstra K, Fitzgibbons JM, Yoon JS. Is episodic memory performance more vulnerable to depressive affect in older adulthood? Neuropsychol Dev Cogn B Aging Neuropsychol Cogn. 2019;26(2):24463.

4 Mitchell AJ, Subramaniam H. Prognosis of depression in old age compared to middle age: a systematic review of comparative studies. Am J Psychiatry. 2005;162(9):1588-601.

5 Conwell Y, Duberstein PR, Caine ED. Risk factors for suicide in later life. Biol Psychiatry. 2002;52(3):193-204.
6 Kessing LV. Severity of depressive episodes during the course of depressive disorder. $\mathrm{Br} \mathrm{J}$ Psychiatry. 2008;192(4):290-3.

7 Sim K, Lau WK, Sim J, Sum MY, Baldessarini RJ. Prevention of relapse and recurrence in adults with major depressive disorder: systematic review and meta-analyses of controlled trials. Int J Neuropsychopharmacol. 2015;19(2):pyv076.

8 Yesavage JA. Geriatric depression scale. Psychopharmacol Bull. 1988;24(4):709-11.

9 Balsamo M, Cataldi F, Carlucci L, Padulo C, Fairfield B. Assessment of late-life depression via self-report measures: a review. Clin Interv Aging. 2018; 13:2021-44.

10 Baquero M, Martín N. Depressive symptoms in neurodegenerative diseases. World J Clin Cases. 2015;3(8):682-93.

11 Lopez OL, Becker JT, Sweet RA, Klunk W, Kaufer DI, Saxton J, et al. Psychiatric symptoms vary with the severity of dementia in probable Alzheimer's disease. J Neuropsychiatry Clin Neurosci. 2003;15(3):346-53.
12 Reppermund S, Ising M, Lucae S, Zihl J. Cognitive impairment in unipolar depression is persistent and non-specific: further evidence for the final common pathway disorder hypothesis. Psychol Med. 2009;39(4):603-14.

13 Bhalla RK, Butters MA, Mulsant BH, Begley AE, Zmuda MD, Schoderbek B, et al. Persistence of neuropsychologic deficits in the remitted state of late-life depression. Am J Geriatr Psychiatry. 2006;14(5):419-27.

14 Morimoto SS, Gunning FM, Murphy CF, Kanellopoulos D, Kelly RE, Alexopoulos GS. Executive function and short-term remission of geriatric depression: the role of semantic strategy. Am J Geriatr Psychiatry. 2011;19(2): $115-22$.

15 McKhann GM, Knopman DS, Chertkow H, Hyman BT, Jack CR Jr, Kawas CH, et al. The diagnosis of dementia due to Alzheimer's disease: recommendations from the National Institute on Aging-Alzheimer's Association workgroups on diagnostic guidelines for $\mathrm{Al}$ zheimer's disease. Alzheimers Dement. 2011; $7(3): 263-9$. 
16 Sibille F-X, Verreckt E, Philippot P, Agrigoroaei S, Gobiet P, Mees L, et al. Clinique de la dépression chez la personne âgée. Dépression; gériatrie Diabète; autosurveillance glycémique; Freestyle Libre Peau'se dermatologique; médecine interne Cas cliniquesChoc septique. 2019:585.

17 American Psychiatric Association. Diagnostic and statistical manual of mental disorders. 5th ed. Washington, DC: American Psychiatric Association; 2013

18 Alexopoulos GS. Mechanisms and treatment of late-life depression. Transl Psychiatry. 2019;9(1):188.

19 Alexopoulos GS, Kiosses DN, Heo M, Murphy CF, Shanmugham B, Gunning-Dixon F. Executive dysfunction and the course of geriatric depression. Biol Psychiatry. 2005;58(3): 204-10.

20 Elderkin-Thompson V, Mintz J, Haroon E, Lavretsky H, Kumar A. Executive dysfunction and memory in older patients with major and minor depression. Arch Clin Neuropsychol. 2006;21(7):669-76.

21 Beck AT, Steer RA, Brown GK. Beck depression inventory (BDI-II). Pearson; 1996.

22 Radloff LS. The CES-D scale: a self-report depression scale for research in the general population. Appl Psychol Meas. 1977;1(3):385401.

23 Yesavage JA, Brink TL, Rose TL, Lum O, Huang V, Adey M, et al. Development and validation of a geriatric depression screening scale: a preliminary report. J Psychiatr Res. 1982;17(1):37-49.

24 Rajtar-Zembaty A, Sałakowski A, RajtarZembaty J, Starowicz-Filip A. Executive dysfunction in late-life depression. Psychiatr Pol. 2017;51(4):705-18.

25 Lamar M, Charlton R, Zhang A, Kumar A. Differential associations between types of verbal memory and prefrontal brain structure in healthy aging and late life depression. Neuropsychologia. 2012;50(8):1823-9.

26 Lee RS, Hermens DF, Porter MA, RedobladoHodge MA. A meta-analysis of cognitive deficits in first-episode Major Depressive Disorder. J Affect Disord. 2012;140(2):113-24.

27 Lee JS, Potter GG, Wagner HR, Welsh-Bohmer KA, Steffens DC. Persistent mild cognitive impairment in geriatric depression. Int Psychogeriatr. 2007;19(1):125-35.

28 Bhalla RK, Butters MA, Mulsant BH, Begley AE, Zmuda MD, Schoderbek B, et al. Persistence of neuropsychologic deficits in the remitted state of late-life depression. Am J Geriatr Psychiatry. 2006;14(5):419-27.

29 Castaneda AE, Tuulio-Henriksson A, Marttunen M, Suvisaari J, Lönnqvist J. A review on cognitive impairments in depressive and anxiety disorders with a focus on young adults. J Affect Disord. 2008;106(1-2):1-27.

30 Naarding P, Veereschild M, Bremmer M, Deeg D, Beekman AT. The symptom profile of vascular depression. Int J Geriatr Psychiatry. 2009;24(9):965-9.
31 Singh-Manoux A, Akbaraly TN, Marmot M, Melchior M, Ankri J, Sabia S, et al. Persistent depressive symptoms and cognitive function in late midlife: the Whitehall II study. J Clin Psychiatry. 2010;71(10):1379-85.

32 Morimoto SS, Kanellopoulos D, Manning KJ, Alexopoulos GS. Diagnosis and treatment of depression and cognitive impairment in late life. Ann N Y Acad Sci. 2015;1345:36-46.

33 Folstein MF. MMSE: mini-mental state examination: user's guide. PAR; 2001.

34 Reynolds CF 3rd, Kupfer DJ, Hoch CC, Stack JA, Houck PR, Sewitch DE. Two-year followup of elderly patients with mixed depression and dementia. Clinical and electroencephalographic sleep findings. J Am Geriatr Soc. 1986;34(11):793-9.

35 Thomas AJ, Gallagher P, Robinson LJ, Porter RJ, Young AH, Ferrier IN, et al. A comparison of neurocognitive impairment in younger and older adults with major depression. Psychol Med. 2009;39(5):725-33.

36 Elderkin-Thompson V, Moody T, Knowlton B, Hellemann G, Kumar A. Explicit and implicit memory in late-life depression. Am J Geriatr Psychiatry. 2011;19(4):249-55.

37 Leyhe T, Reynolds CF 3rd, Melcher T, Linnemann C, Klöppel S, Blennow K, et al. A common challenge in older adults: classification, overlap, and therapy of depression and dementia. Alzheimers Dement. 2017;13(1): 59-71.

38 Henry J, Crawford JR. A meta-analytic review of verbal fluency deficits in depression. J Clin Exp Neuropsychol. 2005;27(1):78-101.

39 Snyder HR. Major depressive disorder is associated with broad impairments on neuropsychological measures of executive function: a meta-analysis and review. Psychol Bull. 2013;139(1):81-132.

40 Ballmaier M, Kumar A, Thompson PM, Narr KL, Lavretsky H, Estanol L, et al. Localizing gray matter deficits in late-onset depression using computational cortical pattern matching methods. Am J Psychiatry. 2004;161(11): 2091-9.

41 Kohler S, Thomas AJ, Lloyd A, Barber R, Almeida OP, O'Brien JT. White matter hyperintensities, cortisol levels, brain atrophy and continuing cognitive deficits in late-life depression. Br J Psychiatry. 2010;196(2):143-9.

42 Drevets WC. Neuroimaging and neuropathological studies of depression: implications for the cognitive-emotional features of mood disorders. Curr Opin Neurobiol. 2001;11(2): 240-9.

43 Yonelinas AP, Ranganath C, Ekstrom AD, Wiltgen BJ. A contextual binding theory of episodic memory: systems consolidation reconsidered. Nat Rev Neurosci. 2019;20(6): 364-75.

44 Deuker L, Olligs J, Fell J, Kranz TA, Mormann F, Montag C, et al. Memory consolidation by replay of stimulus-specific neural activity. J Neurosci. 2013;33(49):19373-83.
45 Taylor JR, Buratto LG, Henson RN. Behavioral and neural evidence for masked conceptual priming of recollection. Cortex. 2013; 49(6):1511-25.

46 McKee BL, Kelley AE, Moser HR, Andrzejewski ME. Operant learning requires NMDAreceptor activation in the anterior cingulate cortex and dorsomedial striatum, but not in the orbitofrontal cortex. Behav Neurosci. 2010;124(4):500.

47 Zahodne LB, Bowers D, Price CC, Bauer RM, Nisenzon A, Foote KD, et al. The case for testing memory with both stories and word lists prior to dbs surgery for Parkinson's Disease. Clin Neuropsychol. 2011;25(3):348-58.

48 Fletcher PC, Henson RN. Frontal lobes and human memory: insights from functional neuroimaging. Brain. 2001;124(5):849-81.

49 Kim YK, Han KM. Neural substrates for late-life depression: a selective review of structural neuroimaging studies. Prog Neuropsychopharmacol Biol Psychiatry. 2021; 104:110010.

50 Alexopoulos GS. The vascular depression hypothesis: 10 years later. Biol Psychiatry. 2006; 60(12):1304-5.

51 Butters MA, Young JB, Lopez O, Aizenstein HJ, Mulsant BH, Reynolds CF, et al. Pathways linking late-life depression to persistent cognitive impairment and dementia. Dialogues Clin Neurosci. 2008;10(3):345-57.

52 Gasser A-I, Salamin V, Zumbach S. Late life depression or prodromal Alzheimer's disease: which tools for the differential diagnosis? Encephale. 2018;44(1):52-8.

53 Perry RJ, Hodges JR. Fate of patients with questionable (very mild) Alzheimer's disease: longitudinal profiles of individual subjects' decline. Dement Geriatr Cogn Disord. 2000; 11(6):342-9.

54 Petersen RC. Mild cognitive impairment. Continuum. 2004;10(1):9-28.

55 Anderson ND. State of the science on mild cognitive impairment (MCI). CNS Spectr. 2019;24(1):78-87.

56 Brambati SM, Belleville S, Kergoat M-J, Chayer C, Gauthier S, Joubert S. Single-and multiple-domain amnestic mild cognitive impairment: two sides of the same coin. Dement Geriatr Cogn Disord. 2009;28(6):541-9.

57 Zahodne LB, Stern Y, Manly JJ. Depressive symptoms precede memory decline, but not vice versa, in non-demented older adults. J Am Geriatr Soc. 2014;62(1):130-4.

58 Jorm A F. Is depression a risk factor for dementia or cognitive decline. Gerontology. 2000;46:219-27.

59 Perry DC, Datta S, Miller ZA, Rankin KP, Gorno-Tempini ML, Kramer JH, et al. Factors that predict diagnostic stability in neurodegenerative dementia. J Neurol. 2019;266(8): 1998-2009.

60 Jorm AF. Is depression a risk factor for dementia or cognitive decline? Gerontology. 2000;46(4):219-27. 
61 Lehrner J, Coutinho G, Mattos P, Moser D, Pflüger M, Gleiss A, et al. Semantic memory and depressive symptoms in patients with subjective cognitive decline, mild cognitive impairment, and Alzheimer's disease. Int Psychogeriatr. 2017;29(7):1123-35.

62 Panza F, Frisardi V, Capurso C, D'Introno A, Colacicco AM, Imbimbo BP, et al. Late-life depression, mild cognitive impairment, and dementia: possible continuum? Am J Geriatr Psychiatry. 2010;18(2):98-116.

63 Rapp MA, Schnaider-Beeri M, Purohit DP, Perl DP, Haroutunian V, Sano M. Increased neurofibrillary tangles in patients with Alzheimer disease with comorbid depression. Am J Geriatr Psychiatry. 2008;16(2):168-74.

64 Bazin N, Bratu L. (Depression in the elderly: prodroma or risk factor for dementia? A critical review of the literature). Geriatr Psychol Neuropsychiatr Vieil. 2014;12(3):289-97.

65 Belleville S, Gauthier S, Lepage E, Kergoat MJ, Gilbert B. Predicting decline in mild cognitive impairment: a prospective cognitive study. Neuropsychology. 2014;28(4):643-52.

66 Jessen F, Wiese B, Bickel H, Eiffländer-Gorfer S, Fuchs A, Kaduszkiewicz H, et al. Prediction of dementia in primary care patients. PLoS One. 2011;6(2):e16852.

67 Ezzati A, Katz MJ, Derby CA, Zimmerman ME, Lipton RB. Depressive symptoms predict incident dementia in a community sample of older adults: results from the einstein aging study. J Geriatr Psychiatry Neurol. 2019: 891988718824036.

68 Richard E, Reitz C, Honig LH, Schupf N, Tang MX, Manly JJ, et al. Late-life depression, mild cognitive impairment, and dementia. JAMA Neurol. 2013;70(3):374-82.
69 Gracia-Garcia P, de-la-Camara C, Santabarbara J, Lopez-Anton R, Quintanilla MA, Ventura T, et al. Depression and incident Alzheimer disease: the impact of disease severity. Am J Geriatr Psychiatry. 2015;23(2):119-29.

70 Mirza SS, Wolters FJ, Swanson SA, Koudstaal PJ, Hofman A, Tiemeier H, et al. 10-year trajectories of depressive symptoms and risk of dementia: a population-based study. Lancet Psychiatry. 2016;3(7):628-35.

71 Kida J, Nemoto K, Ikejima C, Bun S, Kakuma $\mathrm{T}$, Mizukami K, et al. Impact of depressive symptoms on conversion from mild cognitive impairment subtypes to alzheimer's disease: a Community-Based Longitudinal Study. J Alzheimers Dis. 2016;51(2):405-15.

72 Defrancesco M, Marksteiner J, Kemmler G, Fleischhacker WW, Blasko I, Deisenhammer EA. Severity of depression impacts imminent conversion from mild cognitive impairment to alzheimer's disease. J Alzheimers Dis. 2017; 59(4):1439-48.

73 Ohanna I, Golander H, Barak Y. Does late onset depression predispose to dementia? A retrospective, case-controlled study. Compr Psychiatry. 2011;52(6):659-61.

74 Heser K, Tebarth F, Wiese B, Eisele M, Bickel $\mathrm{H}$, Köhler M, et al. Age of major depression onset, depressive symptoms, and risk for subsequent dementia: results of the German study on Ageing, Cognition, and Dementia in Primary Care Patients (AgeCoDe). Psychol Med. 2013;43(8):1597-610.

75 Dillon C, Tartaglini MF, Stefani D, Salgado P, Taragano FE, Allegri RF. Geriatric depression and its relation with cognitive impairment and dementia. Arch Gerontol Geriatr. 2014; 59(2):450-6.
76 Tapiainen V, Hartikainen S, Taipale H, Tiihonen J, Tolppanen AM. Hospital-treated mental and behavioral disorders and risk of $\mathrm{Al}-$ zheimer's disease: a nationwide nested casecontrol study. Eur Psychiatry. 2017;43:92-8.

77 Barnes DE, Yaffe K, Byers AL, McCormick M, Schaefer C, Whitmer RA. Midlife vs late-life depressive symptoms and risk of dementia. differential effects for alzheimer disease and vascular dementia. Arch Gen Psychiatry. 2012;69(5):493-8.

78 Shdo SM, Ranasinghe KG, Sturm VE, Possin KL, Bettcher BM, Stephens ML, et al. Depressive symptom profiles predict specific neurodegenerative disease syndromes in early stages. Front Neurol. 2020;11:446.

79 Harrington KD, Lim YY, Gould E, Maruff P Amyloid-beta and depression in healthy older adults: a systematic review. Aust N Z J Psychiatry. 2015;49(1):36-46.

80 Lloyd AJ, Ferrier IN, Barber R, Gholkar A, Young AH, O'Brien JT. Hippocampal volume change in depression: late-and early-onset illness compared. Br J Psychiatry. 2004;184(6) 488-95.

81 Byers AL, Yaffe K. Depression and risk of developing dementia. Nat Rev Neurol. 2011; 7(6):323-31.

82 Donovan NJ, Amariglio RE, Zoller AS, Rudel RK, Gomez-Isla T, Blacker D, et al. Subjective cognitive concerns and neuropsychiatric predictors of progression to the early clinical stages of Alzheimer disease. Am J Geriatr Psychiatry. 2014;22(12):1642-51. 